\title{
Widening participation - a comparison of the characteristics of successful UK applicants to the five-year and four-year dental programmes in 2007 and 2008
}

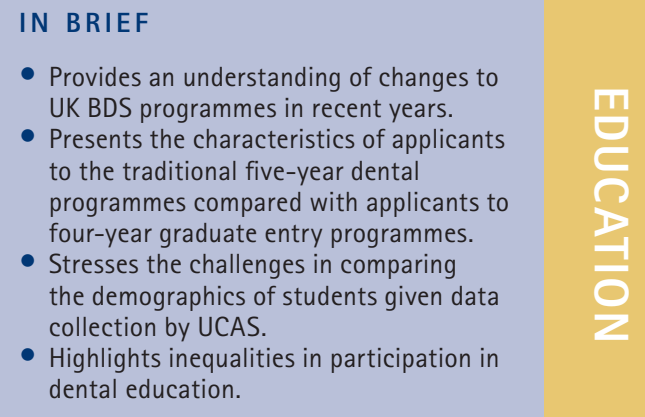

\author{
V. Niven, ${ }^{* 1}$ L. B. Cabot ${ }^{2}$ and J. E. Gallagher ${ }^{1}$ \\ VERIFIABLE CPD PAPER
}

Aim To compare the demographics (age, sex, ethnicity, social status, disability, country/region) and academic experience (school type) of accepted UK applicants to the five-year and four-year dental programmes in 2007 and 2008. Methods Retrospective descriptive analysis was carried out on the University and College Admissions Services (UCAS) data for accepted UK applicants to the five- and four-year dental programmes at UK dental schools in the years 2007 and 2008. Logistic regression was used to model the outcome of dental admission to programmes (four-year vs five-year), controlling for the other explanatory variables. Data were analysed using SPSS v19. Results In the years 2007 and 2008 over 2,000 UK applicants were accepted on to a dental course $(n=2,274)$ within the UK. Of these accepted applicants, $84 \%(n=1,903)$ were accepted onto a five-year and $14 \%(n=322)$ onto a four-year, programme. Over half were female for both the five- and four-year programmes (58\% cf 59\% respectively). One tenth of students accepted to the five-year programme were 'mature' $(n=173)$ and nearly all of the students to the four-year programme $(n=321)$. Similar proportions of accepted applicants to both programmes were from minority ethnic groups (46\%), with the majority of students being of White or Asian background; however, the four-year programmes accepted a higher proportion of black (4\% cf 1\%) and 'other' minority ethnic students ( $8 \%$ cf $3 \%$ ) when compared with the five-year programme. A higher proportion of accepted students to the four-year programmes came from the lowest 'higher/further education participation areas' (POLAR2 groups 1-3) than the five-year programmes (38\% cf 28\%). Proportionally more accepted applicants to the four-year programmes came from London than the five-year programmes (30\%, cf 20\%). In contrast, a greater proportion of accepted applicants to the five-year programmes came from Scotland (13\% cf 6\%), Northern Ireland (9\% cf 0\%) and Wales (4\% cf 2\%). When all other factors were controlled, the odds of being accepted to the four-year rather than the five-year programme were higher if the applicants were mature and from Greater London. Conclusion There is little definitive evidence that graduate entry programmes widen access to dentistry when compared with the traditional five-year programme; however, the findings do highlight geographic disparities in access to graduate entry programmes, which are important for policy makers and schools to consider.

\section{INTRODUCTION}

Widening participation (WP) in higher education is an important factor in education policy. WP can be considered as increasing diversity and representation of students who have not traditionally accessed higher education. ${ }^{1}$ In recent years we have seen an increase in undergraduate numbers and

'King's College London Dental Institute at Guy's, King's College and St Thomas' Hospitals, Unit of Oral Health Services Research \& Dental Public Health, Denmark Hill Campus, Bessemer Road, London, SE5 9RS; '2King's College London Dental Institute at Guy's, King's College and St Thomas' Hospitals, Department of Prosthodontics, Floor 25, Tower Wing, Guy's Hospital, London, SE1 9RT

*Correspondence to: Victoria Niven

Email: victoria.niven@kcl.ac.uk; Tel: 02032993481

\section{Refereed Paper}

Accepted 29 October 2012

DOI: 10.1038/sj.bdj.2013.107

${ }^{\circledR}$ British Dental Journal 2013; 214: 117-122 specific local WP initiatives, the introduction of four-year graduate and professional entry programmes and the opening of three graduate-only dental schools. ${ }^{2}$

One significant challenge to WP has been the introduction of student fees, which vary across the constituent countries of the UK - these were first introduced in 1998, rose to over £3,000 per year in 2004, and in England and Wales in 2012 these have risen to a maximum of £9,000 per annum. Scottish domiciled students are not required to pay fees at Scottish universities and with the desire to retain the dental workforce in Scotland and the introduction of graduate entry programmes various bursary schemes have been available to certain categories of student over much of the past decade. ${ }^{3}$ Ironically, the recent increase in tuition fees in England and Wales is conditional on a significant proportion of this fee being spent on WP initiatives. ${ }^{4}$ We can only speculate as to the impact this recent change will have on WP, however, we do know that applicant numbers for medicine and dentistry have fallen for 2012 entry. ${ }^{5}$

Dentistry, to some extent, has followed its medical counterparts in expanding student numbers and promoting a widening access agenda. Both medicine and dentistry attract, and admit a higher proportion of students from socially advantaged backgrounds, albeit that dentistry has done rather better in attracting students from state schools than its medical counterparts. ${ }^{6}$ 
There is limited evidence from medicine that graduate entry programmes are having success in increasing the representation of students who haven't traditionally entered higher education in several institutions. Powis et al. ${ }^{7}$ suggested that graduate entry programmes in medicine have increased the diversity of the student body and highlighted the closer match between the background of medical graduate entry students and the general population when a comparison is made with traditional five-year programmes. ${ }^{7}$ James et al. $^{8}$ from Nottingham, a medical school that has a traditional five-year and fouryear programme, reported that graduate entry applicants were more likely to come from lower socio-economic backgrounds (using the Townsend Index and student's home postcodes) and the accepted applicants were likely to be significantly older - beyond that expected of having undertaken an initial qualification.

Research to date has considered applicants and/or successful applicants to dentistry as a whole. ${ }^{6,9-11}$ In recent years dentistry has proved attractive to ethnic minority applicants, particularly Asian applicants, while black students are under-represented when compared with the UCAS applicant population as a whole. ${ }^{6}$ Dentistry also tends to attract more applicants from selective and independent schools and also a greater proportion of those from higher socioeconomic groups when compared with those applying to higher education generally, albeit to a lesser extent than medicine. ${ }^{6,9,10}$

Now that the graduate-entry programmes in dentistry are established, and before the effects of the introduction of higher fees can be ascertained, it is important to assess who is entering these four-year programmes, how the applicants differ from those on traditional five-year programme and to what extent there is any evidence of WP.

\section{AIM}

To compare the characteristics (age, sex, ethnicity, social status, country/region) and academic experience (school type) of accepted UK applicants with the five- and four-year dental programmes in 2007 and 2008.

\section{MATERIALS AND METHODS}

University and Colleges Admissions Service (UCAS) is the central organisation through

Table 1 Number and proportion of accepted UK applicants to five- and four-year (and three-/six-year) programmes by sex and maturity, 2007 and $2008(n=2274)$

\begin{tabular}{|c|c|c|c|c|c|c|}
\hline & & Prograr & & & & \\
\hline & & 5-year & 4-year & Total & 3-/6-year & Total \\
\hline Female & Number & 1,101 & 171 & 1,272 & 33 & 1,305 \\
\hline & Percentage & 58 & 59 & 57 & 67 & 57 \\
\hline Male & Number & 802 & 151 & 953 & 16 & 969 \\
\hline & Percentage & 42 & 41 & 43 & 33 & 43 \\
\hline Total & Number & 1,903 & 322 & 2,225 & 49 & 2,274 \\
\hline$<21$-years-old & Number & 1,730 & & 1,731 & 26 & 1,757 \\
\hline & Percentage & 91 & 0 & 78 & 53 & 77 \\
\hline$>21$-years-old & Number & 173 & 321 & 494 & 23 & 517 \\
\hline & Percentage & 9 & 100 & 22 & 47 & 23 \\
\hline
\end{tabular}

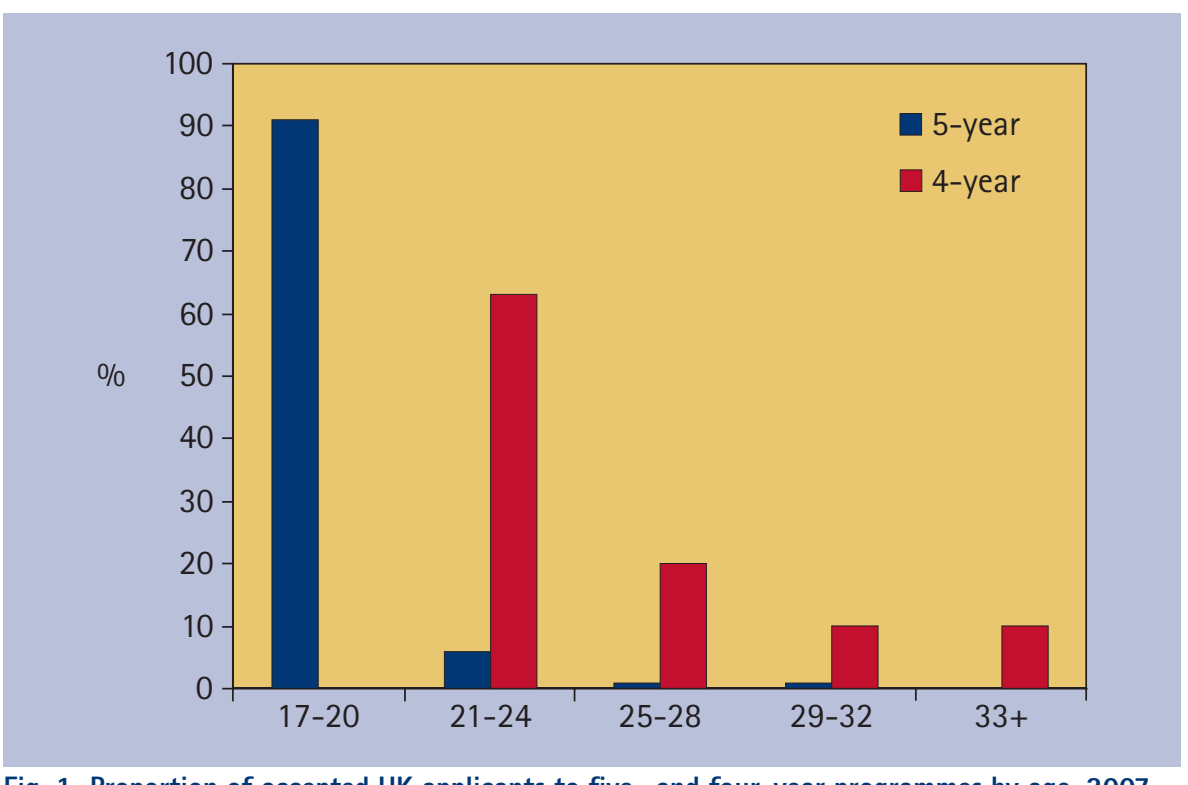

Fig. 1 Proportion of accepted UK applicants to five- and four-year programmes by age, 2007 and $2008(n=2,225)$

which applicants are processed for entry to full-time higher education programmes in the UK. UCAS provided data on all successful applicants to a dental programme for the academic years beginning 2007 and 2008. 'Successful applicants' refers to students who were offered, accepted and enrolled on a UK dental course. UCAS provided data on whether an individual successful applicant had been accepted to specific course codes. Using information on course codes it was possible to identify students accepted for five-year and four-year programmes. The remainder, which amounted to 49 students, comprised of those entering three- or six-year programmes. As these programmes are recorded as the same code on the UCAS application form, the applicants cannot be differentiated as to whether they were accepted on to the three-year, or on to the six-year programme. However, some data from this course code are included in the descriptive analysis for comparison. In addition, accepted applicants for whom UCAS did not provide details of the course group were excluded from the analyses. Ethics committee approval was not required for this study.

Using the UCAS classification, applicants of 21 years of age or over were classified as 'mature'. Socioeconomic status was provided according to the professional background of the head of the applicant's household and UCAS assigns social status according to a simplified version of the National Statistics Socioeconomic Classification 2001 (employment status 


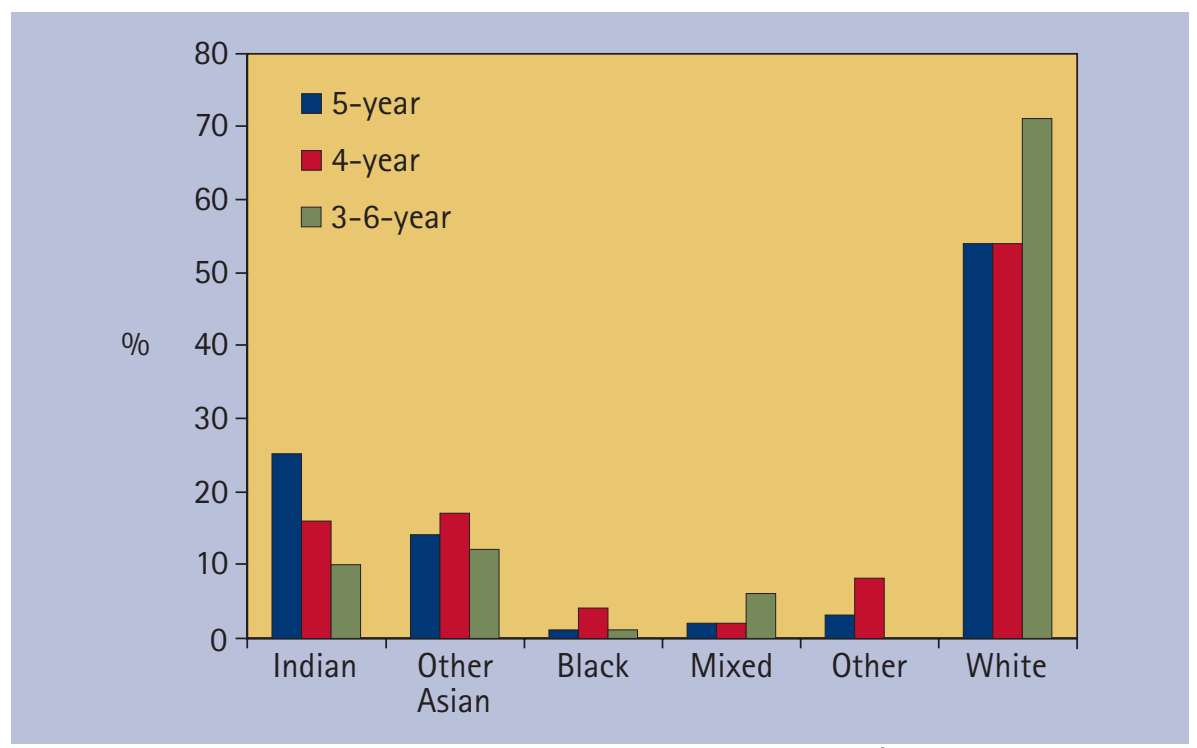

Fig. 2 Proportion of accepted UK applicants to five-, four- and three-/six- year programmes by ethnic group, 2007 and $2008(n=2,274)$

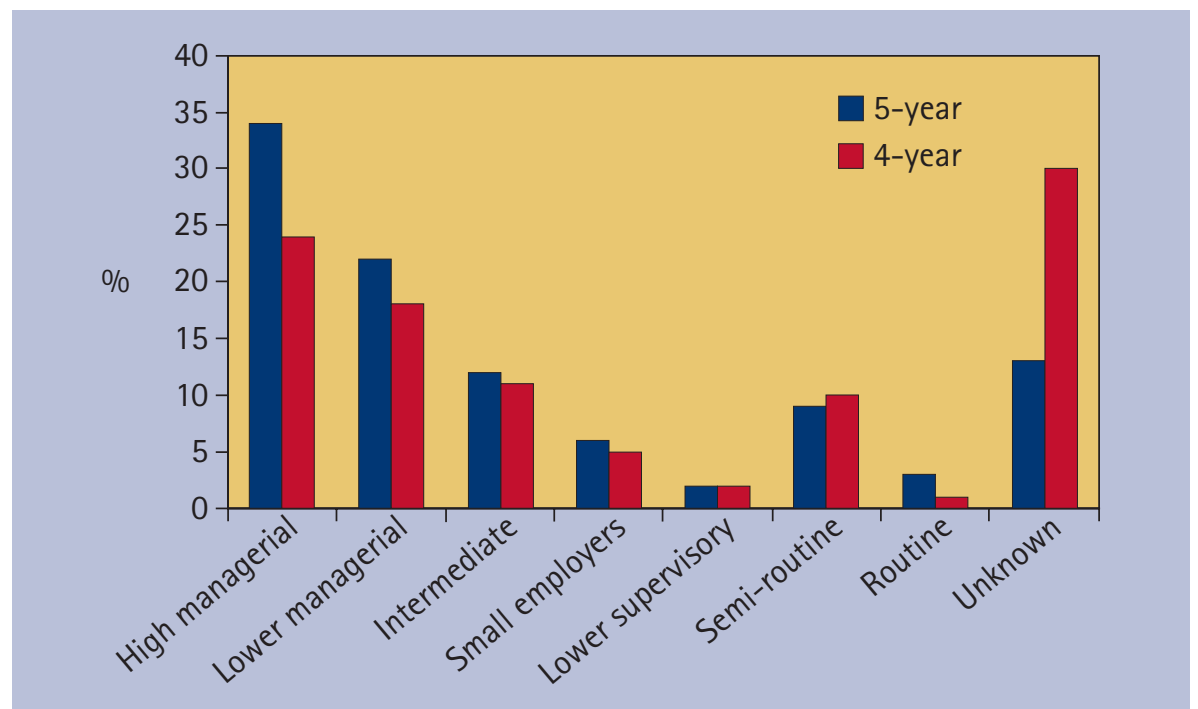

Fig. 3 Proportion of accepted UK applicants to five- and four-year programmes by SEG, 2007 and $2008(n=2,225)$

and size of organisation information is not collected), using the Standard Occupational Classification 2000. Socioeconomic grouping is categorised according to the profession of the head of household. UCAS derived school type from the National Schools register.

The POLAR2 classification, as created by HEFCE, ${ }^{12}$ is based upon the participation of young people who were aged 18 years between 2000 and 2004 and entered a higher education (HE) course in a UK HE institution or GB further education (FE) institution. The classification ranks wards by their young participation rates in HE/ $\mathrm{FE}$, giving five quartile groups of area ordered from one (those wards with the lowest participation rate) to five (those had favoured medicine in their application.

Of all the accepted applicants in the time period $94.6 \%$ were from the UK ( $n=2,274)$. Of these accepted UK applicants $84 \%(\mathrm{n}=1,903)$ were accepted to a five-year programme and 14\% ( $\mathrm{n}=322)$ to a four-year programme. Of the remaining 49 applicants, an estimated 16 were accepted to the three-year programme for medical graduates, thus 33 will have entered a six-year programme.

\section{Age and sex}

Of the accepted UK applicants over the two entry years, over half were female: $58 \%$ of the five-year, 59\% of the four-year and $67 \%$ of the three-/six-year programmes (Table 1). As expected, nearly all the accepted applicants to the four-year programmes were mature students (over the age of 20 years) as they were graduate entry in nature. This compares with one tenth of the accepted applicants to five-year (9\%) and nearly one quarter of the three-/six-year programme (23\%). However, the age profile of the cohort of students accepted to the four-year programmes was older than that of the five-year programmes (Fig. 1).

\section{Ethnicity}

Both types of programme accepted 46\% of applicants from minority ethnic groups (cf 29\% for the three-/six-year programmes), with the majority of students being of White or Asian background; however, the four-year programmes accepted a higher proportion of black students (4\% and 1\% respectively) and other ethnic students (9\% and 3\% respectively) than the five-year programmes (Fig. 2).

of the Asian students accepted to the five-year programmes a greater proportion were from the Indian group (65\%; $\mathrm{n}=751$ ) than for the four-year programmes (49\%; $\mathrm{n}=102)$.

\section{Socioeconomic group (SEG)}

A greater proportion of accepted UK applicants to the five-year programmes were from the three higher socioeconomic groups (I higher managerial, II lower managerial and III intermediate occupations) than to the four-year programmes in 2007 and 2008 (68\% and 53\%). However, nearly one third of accepted applicants to the four-year programmes (30\%) did not 
declare, or did not know, their socioeconomic grouping (Fig. 3).

\section{POLAR2}

More students who were accepted to the dental graduate entry and the three-/ six-year programmes were from areas with lower participation in HE/FE than to the five-year programmes (38\% POLAR2 groups 1-3 and 28\%) (Table 2).

\section{School type}

Of the accepted applicants to the four-year dental programmes, 59\% declared their school type as 'other' compared with 5\% of the five-year programmes (Fig. 4).

\section{Region}

Proportionally more accepted applicants to the four-year programmes came from London than for the five-year programmes (30\% cf 20\%) and also from the South West (11\% cf 4\%) as shown in Figure 5. In contrast, a greater proportion of accepted applicants to the five-year programmes came from Scotland (13\% cf 6\%), Northern Ireland and Wales (13\% cf 2\%) (Table 3).

\section{Multivariate analysis}

The results of the logistic regression analysis for the acceptance to dentistry are presented in Table 4. Unsurprisingly, the probability of being accepted to the four-year rather than the five-year programmes was associated with the level of maturity ( $p<0.001$ ) but interestingly also the UK region ( $p=0.002)$. The HosmerLemeshow test suggests that the model fits the data (Chi-squared $=16.96, \mathrm{p}=0.031$ ). As expected, the odds of being accepted to the four-year rather than the five-year programmes increased if the student was mature.

The odds of being accepted to four-year rather than the five-year programmes decreased by over 25-fold for accepted applicants from Northern Ireland compared with Greater London (OR $=0.04,95 \%$ CI 0.004 to $0.351, p=0.004$ ) and over 3-fold for accepted applicants from Scotland compared with Greater London $(\mathrm{OR}=0.29$, 95\% CI 0.128 to $0.659, \mathrm{p}=0.003$ ).

\section{DISCUSSION}

The findings of this paper suggest that four-year graduate programmes attract a higher proportion of students from wards

Table 2 Accepted UK applicants to five-, four- and three-/six-year programmes by POLAR2 category, 2007 and $2008(n=2,274)$

\begin{tabular}{|l|lll|ll}
\hline \multicolumn{2}{l}{ POLAR2 } & \multicolumn{2}{c}{ Classification } & Programmes \\
\hline Unknown & Percentage & 1 & 1 & 2 \\
\hline 5 & Number & Highest quintile HE/FE participation wards & 920 & 117 & 15 \\
\hline & Percentage & 48 & 36 & 31 \\
\hline 4 & Number & 443 & 79 & 14 \\
\hline & Percentage & 23 & 25 & 29 \\
\hline $1-3$ & Number & 527 & 123 & 19 \\
\hline & Percentage & Lowest quintile HE/FE participation wards & 28 & 38 & 38 \\
\hline Total & Number & 1,903 & 322 & 49 \\
\end{tabular}

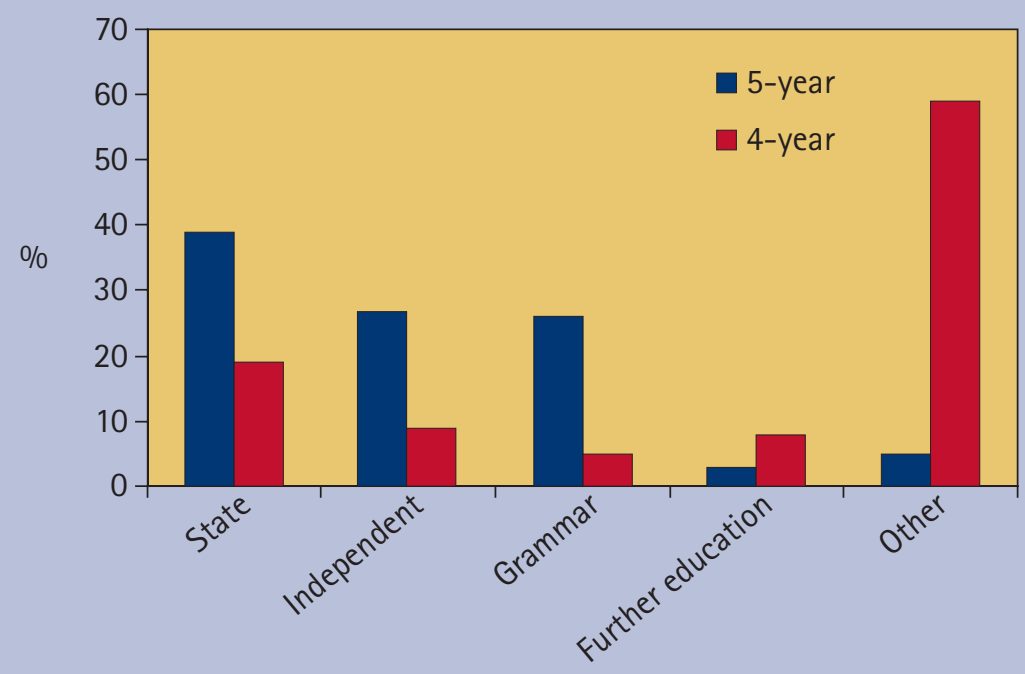

Fig. 4 Proportion of accepted UK applicants to five- and four-year programmes by school type, 2007 and $2008(n=2,225)$

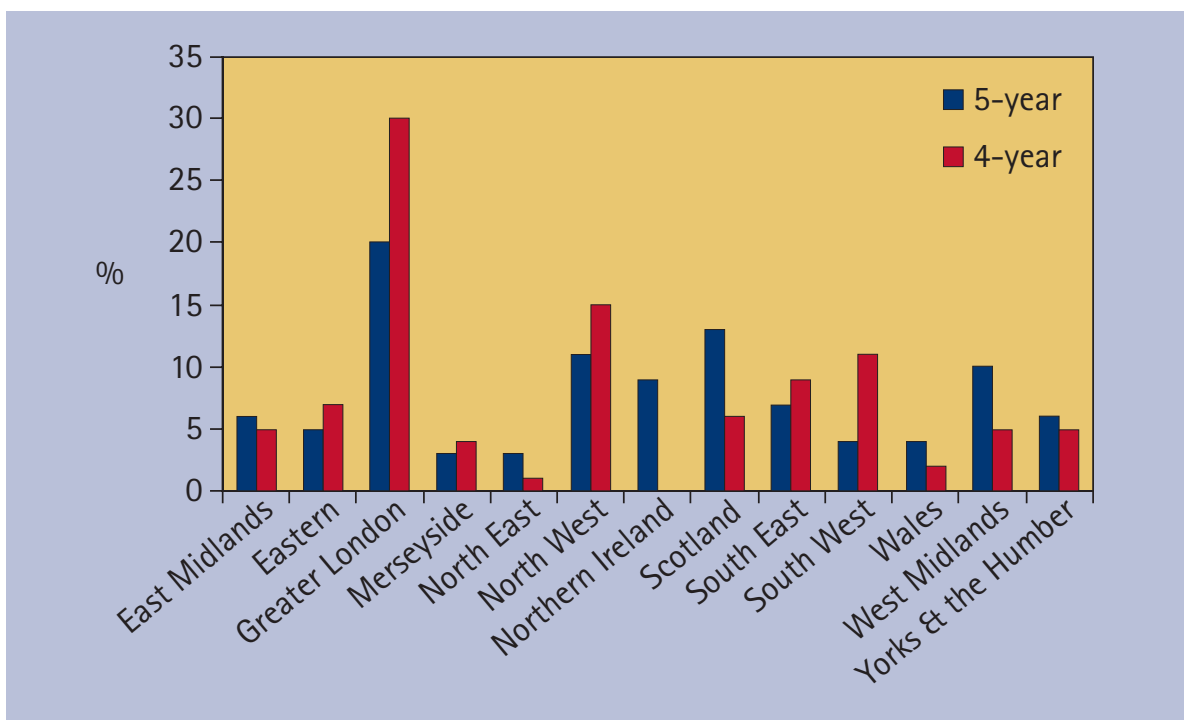

Fig. 5 Proportion of accepted UK applicants to five- and four-year programmes by UK region, 2007 and $2008(n=2,225)$

where there is historically lower participation in higher/further education, a slightly different ethnic mix than the traditional five-year programme and an older age profile. While there isn't evidence of widening participation in relation to sex, school-type and SEG there is no evidence that the four-year programme impacts 
Table 3 Proportion and number of accepted UK applicants to five- and four-year

(and three-/six-year) programmes by UK country/region, 2007 and $2008(n=2,274)$

\begin{tabular}{|c|c|c|c|c|c|c|}
\hline \multirow{2}{*}{\multicolumn{2}{|c|}{ Region }} & \multicolumn{5}{|c|}{ Programmes } \\
\hline & & \multirow{2}{*}{$\begin{array}{l}5 \text {-year } \\
379\end{array}$} & \multirow{2}{*}{$\begin{array}{l}\text { 4-year } \\
96\end{array}$} & \multirow{2}{*}{$\begin{array}{l}\text { Total } \\
475\end{array}$} & \multirow{2}{*}{$\begin{array}{l}3-/ 6 \text {-year } \\
13\end{array}$} & \multirow{2}{*}{$\begin{array}{l}\text { Total } \\
488\end{array}$} \\
\hline Greater London & Number & & & & & \\
\hline & Percentage & 20 & 30 & 21 & 27 & 22 \\
\hline \multirow[t]{2}{*}{ England (ex Greater London) } & Number & 1,031 & 198 & 1,229 & 27 & 1,256 \\
\hline & Percentage & 54 & 61 & 55 & 55 & 55 \\
\hline \multirow[t]{2}{*}{ Northern Ireland and Wales } & Number & 253 & 9 & 262 & 9 & 271 \\
\hline & Percentage & 13 & 2 & 12 & 18 & 12 \\
\hline \multirow[t]{2}{*}{ Scotland } & Number & 240 & 19 & 259 & 0 & 259 \\
\hline & Percentage & 13 & 6 & 12 & 0 & 11 \\
\hline Total & Number & 1,903 & 322 & 2225 & 49 & 2,274 \\
\hline
\end{tabular}

Table 4 Multiple logistic regression for acceptance applicants to four- vs five-year programmes by UK country/region, 2007 and $2008(n=2,225)$

\begin{tabular}{|c|c|c|c|c|}
\hline \multirow[b]{2}{*}{ Variable } & \multirow[t]{2}{*}{ Sig. } & \multirow[t]{2}{*}{$\operatorname{Exp}(B)$} & \multicolumn{2}{|c|}{ 95\% $\mathrm{Cl}$ for $\operatorname{EXP(B)}$} \\
\hline & & & Lower & Upper \\
\hline Maturity & 0.000 & 3,338.116 & 443.832 & $25,106.377$ \\
\hline Sex & 0.942 & 1.015 & 0.681 & 1.512 \\
\hline Ethnicity & 0.286 & & & \\
\hline Black vs Asian & 0.429 & 0.821 & 0.504 & 1.338 \\
\hline Mixed vs Asian & 0.422 & 1.627 & 0.495 & 5.346 \\
\hline Other vs Asian & 0.208 & 0.409 & 0.102 & 1.646 \\
\hline White vs Asian & 0.208 & 1.716 & 0.741 & 3.972 \\
\hline SEG & 0.721 & & & \\
\hline Lower managerial vs higher managerial (HM) & 0.659 & 1.148 & 0.621 & 2.122 \\
\hline Intermediate vs HM & 0.537 & 1.272 & 0.592 & 2.733 \\
\hline Small employers vs HM & 0.205 & 2.278 & 0.637 & 8.146 \\
\hline Lower supervisory vs HM & 0.460 & 0.628 & 0.183 & 2.159 \\
\hline Semi-routine vs HM & 0.817 & 1.095 & 0.509 & 2.353 \\
\hline Routine vs HM & 0.556 & 0.639 & 0.144 & 2.834 \\
\hline Unknown vs HM & 0.548 & 0.852 & 0.505 & 1.438 \\
\hline School & 0.155 & & & \\
\hline Independent vs state & 0.843 & 0.928 & 0.443 & 1.942 \\
\hline Grammar vs state & 0.693 & 1.222 & 0.451 & 3.311 \\
\hline FE vs state & 0.176 & 0.608 & 0.296 & 1.249 \\
\hline Other vs state & 0.285 & 1.333 & 0.787 & 2.258 \\
\hline Region & 0.002 & & & \\
\hline Rest of England vs GL & 0.109 & 0.656 & 0.391 & 1.098 \\
\hline N. Ireland vs GL & 0.004 & 0.040 & 0.004 & 0.351 \\
\hline Scotland vs GL & 0.003 & 0.290 & 0.128 & 0.659 \\
\hline Wales vs GL & 0.357 & 2.471 & 0.361 & 16.931 \\
\hline
\end{tabular}

negatively on the widening participation agenda. However, this paper does raise issues in relation to geographic access as there are potential inequalities in access to graduate entry programmes.

This research explores the dental experience from a national perspective in light of the emerging diversity of programmes in the $\mathrm{UK},{ }^{2}$ while past research has focused on dental applicants as a whole. It thus provides a mirror to policy makers and the profession to inform future decisions, particularly as the widening participation agenda is still on the table. ${ }^{13}$

The (descriptive) findings of this paper confirm that there is good access to dentistry for certain minority ethnic groups and that the four-year programmes may have a slightly more diverse ethnic mix. They are accessed by a higher proportion of students from black and other minority ethnic groups who have traditionally been underrepresented in dentistry when compared with the population in general and those entering HE in particular. ${ }^{6}$ The data also reveal an older cohort of accepted UK applicants to the four-year than the five-year programmes, as is similarly found by James et al. at the Nottingham medical graduate entry programme in $2008 .{ }^{8}$

Interestingly, these results raise other issues in relation to the regional access to dental programmes that are worthy of consideration. First, there is unequal access to graduate entry programmes. This is important because graduate entry students are more mature in age and thus may have partners, families and other commitments that prevent them from moving just to study. Clearly there is good uptake of graduate programmes in London, the South West and North West of England where there are graduate entry programmes available at London institutions, Peninsula Dental School and University of Central Lancashire (UClan) respectively. ${ }^{2}$ Northern Ireland and Wales in particular could consider the possibility of commencing graduate entry programmes that accredit prior learning. Furthermore, it appears that the uptake of dentistry in five-year programmes is less in areas like the South West of England - so should the schools offering only four-year programmes also provide the opportunity for five-year programmes? This is particularly important in areas where there is a need to build up 
the dental workforce as there is evidence emerging that graduate entry students have a strong commitment to contribute to healthcare. ${ }^{14}$ It is important to recognise that increasing numbers of countries are running four-year programmes - this happens in the US where dentistry is a second degree and in just over half of the member states in the Europe Union (14 of the 27 states).

The results of this paper raise questions regarding the information collection of UCAS forms. Socioeconomic group and school type are traditional markers of status, however, these results show graduate entry students did not provide these data (30\% failed to provide information on SEG and 59\% on school type) - an interesting finding. UCAS forms at the time of this data collection requested information on "parent or guardian's occupational background or their own occupation if the student is over 20 years old', ${ }^{15}$ to determine socioeconomic group (SEG). A large proportion of graduate entry programme applicants may have failed to declare this information possibly due to still being on an undergraduate programme at the time of application. However, from 2009 UCAS no longer provides data on SEG and have taken the decision to publish data using POLAR2. ${ }^{16}$

In relation to school type, it will have been some time since their secondary education and thus not all of the students will consider that it is relevant to complete this section. ${ }^{17}$ If school type remains one of the most important markers of social status there is a clear need for UCAS to alter their data collection system to ensure that more students provide this information. Although degree information is collected by UCAS it is not reported in order to protect students' identities, however, some information on whether applicants are current students or graduates would be relevant. As mature applicants may be in higher education at the time of application we propose they should therefore have an option to identify their occupation as 'student in higher education'. For graduate entry students it would also be helpful to have information on their previous school type to be able to effectively monitor WP.
UCAS data would then provide external validation of WP initiatives effectiveness.

Although one third of the four-year and 13\% of the five-year programme entrants did not declare their SEG, of those who did there was evidence that a lower proportion of students to the graduate entry programmes were from higher social classes (53\% cf 68\%). The findings suggest that a greater proportion of students accepted to the graduate entry dental programmes come from areas of lower participation in higher/further education by young people (POLAR2). If they are students or young graduates, however, they may be living in lower participation areas for financial reasons and may have grown up in areas of higher participation; therefore these data need to be cross-referenced with SEG and/or school type before this can be stated conclusively.

Limitations of this analysis must be recognised, including the inability to include a small proportion of graduate entry students in the analysis as they could not be allocated to the three-year programme because of shared coding of different length of programmes by schools, or missing codes. This is something that UCAS should address with dental schools in support of quality monitoring. In addition, as already highlighted, the traditional markers of social status such as occupation of head of household and secondary education are less relevant and therefore less often completed by graduates. It will be important to have high quality data to monitor changes over the forthcoming years, particularly following the introduction of higher fees in England and Wales and the implications for UK dentistry to ensure that participation is widened or maintained, rather than reduced.

\section{CONCLUSION}

There is no definitive evidence that graduate entry programmes widen access to dentistry when compared with traditional five-year programmes; however, the findings highlight geographic disparities in access to graduate entry programmes, which are important for policy makers and schools to consider and need to be effectively monitored.
1. Jones R, Thomas L. The 2003 UK Government highe education white paper: a critical assessment of its implications for the access and widening participation agenda. J Educ Policy 2005; 20: 615-630.

2. Gallagher J, Wilson N. CU@ dental skl. London: Stephen Hancocks Ltd, 2011.

3. NHS Careers. Financial support for students on degree courses in dentistry. NHS, 2011. Online information available at http://www.nhscareers.nhs.uk/ details/Default.aspx?ld=608 (accessed January 2013)

4. Office for Fair Access. OFFA decisions on 2012-2013 access agreements. OFFA, 2011. Online article available at http://www.offa.org.uk/press-releases/ universities-and-colleges-to-increase-their-spending-on-access-to-600-million-a-year/ (accessed January 2013).

5. University and College Admission Services. 2012 applicant figures - October. UCAS, 2012. Online information available at http://www. ucas.ac.uk/about_us/media_enquiries/media_ releases/2011/20111024 (accessed January 2013)

6. Gallagher J, Niven V, Donaldson N, Wilson N H. Widening access? Characteristics of applicants to medical and dental schools, compared with UCAS. Br Dent J 2009; 207: 433-445.

7. Powis D, Hamilton J, McManus I C. Widening access by changing the criteria for selecting medical students. Teach Teach Educ 2007: 23: 1235-1245.

8. James D, Ferguson E, Powis D, Symonds I, Yates J. Graduate entry to medicine: widening academic and socio-demographic access. Med Educ 2008; 42: 294-300.

9. Bedi R, Gilthorpe M S. Ethnic and gender variations in university applicants to United Kingdom medica and dental schools. Br Dent J 2000; 189: 212-215.

10. Bedi R, Gilthorpe M S. Social background of minority ethnic applicants to medicine and dentistry. $\mathrm{Br}$ Dent J 2000; 189: 152-154.

11. Gallagher J E, Clarke W, Eaton K A, Wilson N H Dentistry - a professional contained career in healthcare. A qualitative study of Vocational Dental Practitioners' professional expectations. BMC Oral Health 2007; 7: 16

12. Higher Education Funding Council for England. POLAR - participation of local areas. HEFCE, 2012 Online information available at http://www.hefce ac.uk/whatwedo/wp/ourresearch/polar/ (accessed January 2013).

13. Department for Business Innovation and Skills. Higher Education: students at the heart of the system. London: BIS, 2011. Online article available at https://www.gov.uk/government/uploads/ system/uploads/attachment_data/file/32409/11 944-higher-education-students-at-heart-ofsystem.pdf (accessed January 2013).

14. Newton P Cabot L Wilson N H Gallagher J E. The graduate entry generation: a qualitative study exploring the factors influencing the career expectations and aspirations of a graduating cohort of graduate entry dental students in one London institution. BMC Oral Health 2011; 11: 25.

15. University and College Admission Services. Socioeconomic status (2002 entry onwards). UCAS, 2002 Online definition available at http://www.ucas. com/about_us/stat_services/dictionary_of_terms/s (accessed January 2013).

16. University and College Admission Services. Applicant and accepted applicant socio-economic analysis over six years. UCAS, 2009. Online information available at http://www.ucas.ac.uk/about us/ stat_services/stats_online/data_tables/socioeconomics (accessed January 2013).

17. University and College Admission Services. Educational background. UCAS, 2012. Online definition available at http://www.ucas.com/about_us/stat_services/dictionary_of_terms/e (accessed January 2013). 